\title{
LAS CARRERAS POLÍTICAS DE LOS SENADORES EN URUGUAY: ¿CAMBIOS O CONTINUIDADES ANTE EL TRIUNFO DE LA IZQUIERDA? ${ }^{1}$
}

\author{
Eduardo Bottinelli
}

\begin{abstract}
RESUMO
O artigo discute os determinantes dos diversos tipos de trajetória política, focalizando especificamente o impacto da mudança política nas elites parlamentares do Uruguai após a ditadura militar. Nosso interesse é mostrar o duplo movimento de continuidade político-partidária e de mobilidade interpartidária dos senadores. Esses movimentos são, conforme nossa hipótese, provenientes das mudanças eleitorais em curso. Além disso, analisam-se as modalidades das carreiras políticas desse grupo parlamentar e a circulação entre os postos parlamentares e outros cargos do Estado. O trabalho baseia-se em uma investigação sobre a trajetória dos senadores uruguaios durante o período de 2005 a 2010, comparando-a com legislaturas anteriores, ainda do período posterior à ditadura (1985-2005). Utiliza-se o método de trajetórias biográficas múltiplas, estudando 38 senadores a partir de fontes documentais pessoais, parlamentares e biografias publicadas, assim como pesquisas e entrevistas realizadas diretamente com os parlamentares. O estudo permite identificar padrões comuns nas carreiras desses políticos, assim como explorar as diferenças existentes entre as trajetórias políticas dos senadores dos partidos tradicionais e dos partidos de esquerda.
\end{abstract}

PALAVRAS-CHAVE: elites parlamentares; trajetórias políticas; partidos políticos; Uruguai.

\section{INTRODUCCIÓN}

El proceso de reconstrucción de la democracia uruguaya en los últimos 20 años ha estado marcado por realineamientos políticos e ideológicos que transformaron en la década del 1990 al sistema político bipartidista tradicional hacia un nuevo formato pluripartidista, con dos partidos tradicionales que ocuparon el papel de partidos conservadores-liberales, en contraste a la emergencia de una alianza de organizaciones políticas de izquierda que aglutinó desde las corrientes más radicales hasta el centro del espectro político. En las últimas Elecciones Nacionales, en el año 2004, la izquierda logró acceder al gobierno nacional por primera vez en la historia del país, logrando a su vez mayoría absoluta en ambas cámaras legislativas.

En este marco, el interés del presente trabajo es analizar distintas dimensiones de los cambios

\footnotetext{
1 Investigación financiada por la Comisión Sectorial de Investigación Científica (CSIC) de la Universidad de la República Oriental del Uruguay. Período de investigación: desde marzo de 2005 hasta marzo de 2007.
}

políticos y sociales, el impacto del aumento de representantes de izquierda en la elite política a través del estudio las carreras políticas de las elites parlamentarias de la actual legislatura. Se seleccionó, a su vez, el estudio del Senado o la Cámara Alta del Parlamento. La elección de estudiar el Senado uruguayo en particular es porque conjuga varios aspectos de interés. Se trata de una Cámara Alta en un Estado unitario que representa la Nación ${ }^{2}$ y que es electo de acuerdo al principio de la representación proporcional. Asimismo, la Cámara Alta posee en términos generales miembros que ya tienen carreras políticas más asentadas y duraderas.

Los estudios referidos a la composición social y la conformación de las elites políticas ponen énfasis por lo general en lo que se denomina la profesionalización de la política y la autonomía relativa de la política. Por otro lado, surge también el debate acerca de la existencia o no de una clase política homogénea en algunos aspectos de su 2 A diferencia de los Estados Federales en los que repre-
senta la diversidad de miembros de la Federación.

Rev, Sociol. Polít., Curitiba, v. 16, n. 30, p. 29-43, jun. 2008 
composición social. A su vez las discusiones teóricas sobre la conformación de las elites políticas llevan a preguntarse con frecuencia en qué medida los integrantes de este grupo político tienen status profesionales similares, cuál es el origen social y económico, así como analizar las relaciones sociales y políticas y los recursos que los hombres y mujeres públicos movilizan para incorporarse a la vida política.

Una interrogante frecuente refiere a en qué medida el status profesional, las posiciones de origen y los recursos sociales movilizados por los hombres públicos inciden en las carreras políticas. En este sentido se realizan investigaciones sobre la socialización, reclutamiento, formación, aprendizaje de roles, disposiciones y saberes, diplomas y competencias, principios de las funciones de la representación y de las carreras políticas (OFFERLÉ, 1999).

Tomando definiciones de autores como Mills y Weber se puede llegar a sostener que un político es una persona que desempeña con cierta regularidad un papel en las instituciones políticas tomándolo como una de sus actividades principales y que utiliza este rol como medio de alcanzar el poder. Para esta afirmación se ha tomado la bibliografía clásica del estudio de las elites políticas, así Mills afirma que el político "se trata del hombre que desempeña con mayor o menor regularidad un papel en las instituciones políticas considerándolo, al menos, como una de sus actividades principales” (MILLS, 1987, p. 216). Y Weber define a los políticos como una persona que aspira al poder: "Quien hace política aspira al poder; al poder como medio para la consecución de otros fines (idealistas o egoístas) o al poder 'por el poder', para gozar del sentimiento de prestigio que él confiere” (WEBER, 1984, p. 5).

Dentro de la definición general de "políticos" cabe distinguir al político profesional, el tipo de político profesional que servirá de base en este estudio: "Hay dos formas de hacer de la política una profesión. O se vive 'para' la política o se vive 'de' la política. [...] Generalmente se dan las dos cosas. [...] Quien vive para la política hace de ello su vida en un sentido íntimo. [...] La diferencia entre el vivir para y el vivir de se sitúa, pues, en un nivel mucho más grosero, en el nivel económico" (idem, p. 16-17; sin grifos en el original). Pero también, para entender el alcance del "político profesional" se hace necesario tomar la definición de Mills, quien considera al político profesional como una persona de carrera política, quien se vincula a la política a través de la penetración en los círculos donde se hace política (MILLS, 1987, p. 216).

Otra forma de político a tener en cuenta es el que Mills definió como "intruso político": es el hombre que "ha pasado la mayor parte de su vida activa fuera de las organizaciones estrictamente políticas, y que - depende del caso - se ve introducido en ellas. [...] Su experiencia profesional es apolítica [...]", son personas que ascienden por mecanismos de patronazgo o directamente a cargos públicos ejecutivos (idem, p. 216-217). Es de suponer que el origen social de estos hombres es distinto al origen social de políticos profesionales.

En esta ponencia se entenderá a la elite de poder tomando como base la definición de Mills, quien define la elite del poder de la siguiente forma: "Entendemos por minoría del poder los círculos políticos, económicos y militares que, como un conjunto intrincado de camarillas que se trasladan e imbrican, toman parte de las decisiones que por lo menos tienen consecuencias nacionales. En la medida en que se deciden los acontecimientos nacionales, la elite del poder está constituida por quienes lo deciden” (idem, p. 25).

Los senadores son tomados como parte de la elite, para ello resulta importante tomar la afirmación que sostiene que el Senado por lo general "está integrado por el estrato más alto de la elite política" (GONZÁLEZ, 1993, p. 99). De esta forma, mediante el estudio de la trayectoria política de los senadores se está investigando un sector importante de la elite política uruguaya de los últimos años.

Desde la perspectiva de la profesionalización de la política surge una visión distinta de las elites, donde se sostiene que los regímenes democráticos y pluralistas que asegura un método de selección más abierto y plural de los gobernantes. Según esta perspectiva de análisis, el estudio debe hacerse a través de la aproximación de la forma de profesionalización de los elencos políticos (SERNA, 2005, p. 4). Así, se cree en carreras políticas profesionales, donde se tienen en cuenta los méritos de los individuos al momento de selección de las elites dirigentes.

Desde el punto de vista de la profesionalización de los elencos políticos dirigentes, Best y Cotta 
(2000), en su trabajo sobre la representación del Parlamento en Europa, analizaron el reclutamiento social y las carreras políticas en 11 países europeos entre los años 1848 y 2000. Así describen y analizan cómo los procesos de modernización y la generalización de la democracia en el transcurso del siglo XX llevaron a la sustitución de cuadros políticos tradicionales y estamentales por políticos profesionales, es decir, por personas que se dedicaron a la actividad política como medio de vida y dedicaron su vida a realizar carrera política.

Con la profesionalización de las carreras políticas toma creciente interés el estudio del reclutamiento, así como el estudio de la función del reclutamiento político en los partidos políticos. Este proceso de reclutamiento de los cuadros de los partidos políticos es el que lleva a la selección de la elite dirigente profesional. Así, Norris (1997) analiza el "pasaje al poder" estudiando el reclutamiento legislativo en las democracias avanzadas. Norris realiza una tipología de carreras políticas analizando no sólo el transcurso de la vida política de las carreras estudiadas sino que analiza cómo son los procesos de selección dentro del sistema político, analizando el régimen electoral y el sistema de partidos de cada uno de los países estudiados. Distingue a su vez cómo son los procesos de selección y reclutamiento de los distintos partidos políticos y cuáles son las motivaciones y los recursos de los candidatos. Esta perspectiva incluye debates entorno a distintos aspectos del tema. Así en algunos momentos aparece como un elemento central el estudio del reclutamiento social y político de los dirigentes, se incluye también una discusión acerca de la profesionalización y la autonomía de la política, así como la existencia o no de una clase política homogénea.

Desde la vertiente francesa de investigación (Bourdieu, Blondel, Dogain) también se hace hincapié en el estudio de las carreras políticas y el desarrollo de tipologías de carreras políticas como forma de aproximación al reclutamiento social por parte de los elencos políticos. Así, desde la teoría de los campos desarrollada por Bourdieu (2000), se distingue la formación de un campo social y el campo político. Las elites se estudian desde el campo social y de las relaciones de la elite política con otras elites pertenecientes a otros campos de la sociedad. De esta forma, el estudio del reclutamiento de las elites dirigentes aparece como un tema central para explorar la representación de los distintos campos de la sociedad, así como la heterogeneidad de la representación social de las bases partidarias.

El profesional político se ha desarrollado junto con el desarrollo de los Estado-nación y la extensión de las democracias representativas (SERNA, 2004). Este profesional de la política se va forjando a medida que se fortalecen las democracias. Así va adquiriendo mayor protagonismo caracterizándose por una especialización en las actividades políticas conformando un grupo de políticos que adquieren a la política como actividad principal, asumiendo roles específicos en la estructura político-partidaria y profesionalizándose en actividades políticas (OFFERLÉ, 1999). Estos profesionales pasan a desempeñar la política como forma de vida, pasando a vivir de la política y haciendo de esta su fuente duradera de ingresos (WEBER, 1984).

El trabajo se focaliza en los distintos tipos de trayectoria política. El foco de análisis del artículo es estudiar el impacto del cambio político, en el nivel de las elites parlamentarias en el Uruguay posdictadura. El interés de las mismas, es mostrar en una capa de la elite política, el doble recorrido entre continuidad política partidaria de los dirigentes y la movilidad interpartidaria provenientes de los cambios políticos electorales en curso.

Asimismo se analizan las modalidades de las carreras políticas del elenco parlamentario y la circulación entre los puestos parlamentarios y otros cargos públicos en el Estado. Se aborda pues, desde el momento de inicio a la vida política (edad, partido y puesto), hasta las trayectorias posteriores hasta llegar al Senado. En ese sentido, se analiza por una parte, las relaciones entre la trayectoria parlamentaria en el Senado, con el desempeño previo de cargos públicos electivos (en el Parlamento y el gobierno) y no electivos en el ámbito de la administración del Estado, así como la rotación y movilidad entre los mismos. Por otro, se identifican pautas y diferencias en las carreras políticas entre partidos.

El trabajo se basa en una investigación sobre la trayectoria de los senadores en el Uruguay durante el período 2005-2010 (XLVI Legislatura). En función de ello se utiliza el método de trayectorias biográficas múltiples estudiando 38 senadores que ejercieron la banca en el período, 
con fuentes documentales personales, parlamentarias, biografías publicadas de los políticos, así como encuestas y entrevistas realizadas directamente a los senadores. Se realizaron un total de 12 encuestas autoadministradas directamente a los senadores, además se realizaron 16 entrevistas en profundidad a senadores de los tres partidos políticos con representación en el Senado. Con los datos recabados a través de encuestas, entrevistas y datos secundarios se confeccionó una ficha que resume la información necesaria para reconstruir el reclutamiento social y la trayectoria política de cada Senador. La comparación con las legislaturas anteriores se basa en un estudio realizado para la Monografía Final de la Licenciatura de Sociología de la Facultad de Ciencias Sociales de la Universidad de la República Oriental del Uruguay (BOTTINELLI, 2005), tutoreado por el Dr. Miguel Serna y cuyo trabajo de campo fue ejecutado junto, Juan García y Alejandro Villaró. En esa oportunidad se relevaron 96 trayectorias biográficas para las cuatro legislaturas posteriores a la dictadura militar, legislaturas que van desde el año 1985 hasta el año 2005.

El problema central de la investigación estuvo centrado en reconstruir mediante trayectorias biográficas ciertos aspectos de la trayectoria política que han tenido los senadores que han ocupado su banca en el período posdictatorial y que han permanecido en ellas al menos un año.

Los objetivos generales de la investigación son: 1) mediante trayectorias biográficas reconstruir ciertos aspectos de la trayectoria política que han tenido los senadores que han ocupado su banca en la actual legislatura (2005-2010); 2) a su vez, intentar reconstruir los distintos perfiles para cada uno de los partidos políticos.

El interés de la ponencia es identificar cómo inciden los distintos aspectos del capital social de los senadores como mecanismo de ingreso a la política, así como el tipo de carrera política que llevan adelante.

El universo de estudio está compuesto por los senadores actuantes a partir del 15 de febrero de 2005 y hasta el 31 de diciembre de 2006. En total se reconstruyeron las trayectorias biográficas de 38 senadores actuantes de la actual legislatura, es decir mediante entrevistas en profundidad, encuestas semiestructuradas y biografías se reconstruyó la vida social y política de los sena- dores que formaron parte del universo.

Las fuentes de información utilizadas fueron básicamente de tres tipos: a) entrevistas en profundidad a senadores de la República; b) la realización de encuestas semiestructuradas mediante la implementación de cuestionarios a los legisladores vía personal, telefónica o e-mail; c) biografías políticas, documentos, curriculum vitae personales y entrevistas en medios de comunicación.

Las carreras políticas de los parlamentarios mostraron patrones comunes. La influencia de la experiencia de resistencia y actividad política clandestina durante la dictadura en la conformación de la primera legislatura del Senado postransición democrática surge como un elemento interesante y común a los legisladores.

Las carreras políticas hacia el Senado muestran dos patrones paralelos. Por un lado, la continuidad de las lealtades partidarias a lo largo de las carreras políticas de los dirigentes. Por otro lado, los patrones de larga continuidad de la pertenencia partidaria y renovación de los mandatos legislativos en un segmento significativo de los legisladores, conviven con una alta rotación de parlamentarios en las instancias de realineamiento político-electoral. A su vez, una parte significativa de los senadores, tienen una movilidad y circulación política entre los cargos parlamentarios y ejecutivos.

Asimismo, se observan pautas diferenciales de las trayectorias políticas entre partidos, de acuerdo a su experiencia gubernativa y desempeño electoral. Las carreras políticas de los legisladores de los partidos tradicionales muestran un acceso más temprano a la administración pública y un inicio más temprano al Parlamento. En cambio, las carreras legislativas de los partidos de izquierda cuentan con menos antecedentes en el Parlamento y en la administración pública.

\section{EL PRIMER CARGO PÚBLICO}

El objetivo de esta sección es analizar dentro del marco de la trayectoria política el inicio en los cargos públicos sean estos del tipo electivo o del tipo designativo. Para poder realizar este análisis se construyó el Cuadro 1 el cual muestra la comparación de los distintos tipos de "primer cargo público” ocupado en la actual legislatura (20052010) con las legislaturas anteriores (1985-2005). 
CUADRO 1 - TIPO DE PRIMER CARGO PÚBLICO OCUPADO

\begin{tabular}{|lcc|}
\hline CARGO & $2005-2010$ & $1985-2005$ \\
\hline Diputado & $26 \%$ & $17 \%$ \\
Senador & $16 \%$ & $18 \%$ \\
Intendente & $3 \%$ & $3 \%$ \\
Subsecr etario de Intendencia & $0 \%$ & $1 \%$ \\
Ministro & $3 \%$ & $1 \%$ \\
Subsecr etario de Ministerio & $5 \%$ & $1 \%$ \\
Edil & $26 \%$ & $21 \%$ \\
F uncion ario de organismo o ente & $8 \%$ & $10 \%$ \\
Director de organismo o ente & $5 \%$ & $9 \%$ \\
Presidente de organismo o ente & $3 \%$ & $0 \%$ \\
Asesor de organismo o ente & $3 \%$ & $2 \%$ \\
Decano & $3 \%$ & $1 \%$ \\
Diplomático & $0 \%$ & $1 \%$ \\
Secretario Ejecutivo & $0 \%$ & $2 \%$ \\
Corte Electoral & $0 \%$ & $2 \%$ \\
Militar & $0 \%$ & $1 \%$ \\
Junta Electoral & $0 \%$ & $1 \%$ \\
Sin dato & $0 \%$ & $5 \%$ \\
Total & $100 \%$ & $100 \%$ \\
\hline
\end{tabular}

FUENTE: el autor.

En el análisis general del cuadro se aprecia que los datos más relevantes para la actual legislatura son: el de Edil, el de Diputado y el de Senador en orden decreciente, con $26 \%$, 26\% y $16 \%$ respectivamente. Podría interpretarse como que el primer cargo público que ocuparon los senadores estudiados es de tipo electivo por la ciudadanía, sea a nivel nacional o a nivel departamental. En términos generales, comparando con los datos correspondientes a las legislaturas anteriores, el comportamiento respecto a los cargos públicos ocupados con anterioridad al cargo de Senador es similar.

La suma de estas tres variables para la actual legislatura llega al 68\%, si se agrega el cargo de intendente que es el otro cargo electivo por la ciudadanía registrado en la investigación, se obtiene que el $71 \%$ del universo de estudio inició su carrera en un cargo público electivo. Esta cifra es bastante más alta que la encontrada para las legislaturas anteriores, en aquellos momentos fue del 59\% (idem).

Mientras tanto, el 19\% de los senadores estudiados tuvo como primer cargo público uno del tipo designativo, sea por el Poder Ejecutivo nacional o departamental, pero son cargos en los que la ciudadanía no elige sino que son elegidos por vinculaciones políticas a través de los partidos.

Analizando los datos desde otra perspectiva puede expresarse que el $58 \%$ de los senadores estudiados han ocupado cargos públicos fuera del ámbito parlamentario antes de ingresar en éste. Mientras que el 26\% tuvo su primer cargo público en el Parlamento, pero en la Cámara Baja. Y se torna relevante ese $16 \%$ de senadores cuyo primer cargo público fue justamente el de Senador de la República, es decir que ese porcentaje no tuvo experiencia previa en ningún tipo de cargo público antes de ser electo para el Senado, seguramente como ha sido analizado más arriba puede tratarse de tres tipos de caso: a) hombres de partido que estuvieron en la estructura partidaria por muchos años pero sin ocupar cargos públicos; b) puede tratarse también de hombres nuevos o jóvenes en la política que accedieron de forma rápida al Senado sin haber adquirido experiencia en otros contextos públicos; c) o podría tratarse de hombres ajenos a la actividad político-partidaria al interior del partido, pero que debido a una gran trayectoria personal-profesional acceden rápidamente a altos cargos públicos, sin experiencia pero con el aval de una larga trayectoria profesional.

Finalmente, surge de la investigación que quienes han ocupado cargos públicos a nivel designativo en el Poder Ejecutivo, han sido básicamente los senadores pertenecientes a los partidos tradicionales. Al contrario, los senadores del Frente Amplio han tenido su primera experiencia a nivel de cargo público básicamente en cargos electivos.

\section{CARGOS PÚBLICOS OCUPADOS CON ANTERIORIDAD AL SENADO}

Respecto a los cargos públicos ocupados por los senadores con anterioridad a ejercer su banca en el Senado, cualquiera sea el cargo público que hayan ocupado antes de asumir la primera bancada como senadores, no necesariamente significa que sea inmediatamente antes sino que pudo haber sido en cualquier momento de la vida política antes de llegar al Senado. 
CUADRO 2 - EMPLEO PÚBLICO ANTERIOR OCUPADO POR LOS SENADORES ELEGIDOS PARA EL PERÍODO 2005-2010

\begin{tabular}{|l|c|}
\hline E MPLEO & $\mathbf{2 0 0 5 - 2 0 1 0}$ \\
\hline Diputado & $32 \%$ \\
Intendente & $21 \%$ \\
Ministro & $5 \%$ \\
P residente de la República & $3 \%$ \\
Funcionario de organismo o ente & $3 \%$ \\
Director de organismo o ente & $3 \%$ \\
Presidente de organismo o ente & $5 \%$ \\
Asesor de organismo o ente & $5 \%$ \\
Decano & $3 \%$ \\
No ocupó & $21 \%$ \\
Total & $100 \%$ \\
\hline
\end{tabular}

FUENTE: el autor.

El primer dato destacable es que el 32\% de los senadores tuvieron como cargo público anterior el cargo de Diputado, es decir que ese 32\% muestra una continuidad en el Parlamento, al menos para esta legislatura. Mientras tanto, el 21\% no ocupó ningún cargo, no tuvo ningún tipo de actividad pública con anterioridad al de Senador.

Otro dato destacable es que el $48 \%$ de los cargos públicos ejercidos con anterioridad al Senado fueron ejercidos fuera del ámbito parlamentario. A su vez, de ese $48 \%$, el $27 \%$ fueron cargos públicos por designación, es decir no elegidos mediante el sufragio de la ciudadanía.

Estos datos suponen que los senadores de la actual legislatura (2005-2010) han tenido una dispersión bastante grande en cuanto a los cargos públicos ocupados con anterioridad al Senado. Si bien la categoría de Diputado es la más frecuente, también es frecuente la suma de cargos públicos por designación, lo que habla de una trayectoria política de estos senadores bastante prolongada, al menos en la órbita pública.

Analizando estos datos con los obtenidos para las legislaturas anteriores (idem), se pueden marcar los siguientes aspectos en cuanto a similitudes y diferencias: en la actual legislatura se nota una mayor presencia de senadores sin experiencia previa en cargos públicos que en las anteriores legislaturas. Los cargos públicos ejercidos con anterioridad en la Cámara de Diputados aparecen en forma muy similar. También resulta similar la cantidad proporcional de cargos públicos ejercidos fuera del ámbito parlamentario nacional. Finalmente, surge como un elemento distintivo entre la legislatura actual y las legislaturas anteriores la cantidad proporcional de senadores cuyo cargo público anterior fue ejercido en cargos designativos, en la legislatura actual suman el $27 \%$, mientras que para las legislaturas anteriores eran el 36\%.

Estas similitudes y diferencias pueden ser explicadas por el cambio en la composición del Senado ocurrida con motivo de los resultados electorales y los cambios que estos produjeron. Así, los senadores del Frente Amplio (que en la actual legislatura son mayoría) son personas que no han tenido mayores experiencias en cargos públicos, y menor todavía es la cantidad de senadores frenteamplistas que ocuparon cargos públicos de manera designativa ya que el control de los entes y organismos públicos, así como del Poder Ejecutivo estuvo desde el comienzo de la vida democrática del país hasta el año 2005 en manos de los partidos tradicionales (centro-derecha).

Respecto al comportamiento dentro de los partidos, aproximadamente la mitad de los senadores frenteamplistas han tenido como cargo público anterior al de Senador el cargo de Diputado. A su vez, un tercio de los senadores del Frente Amplio no han tenido experiencia previa en cargos públicos.

Por su parte, los senadores de los partidos tradicionales han tenido una carrera política anterior bastante más presente en la actividad pública que los senadores frenteamplistas. Más de un tercio de los senadores de los partidos tradicionales han tenido como actividad pública anterior el ser Intendentes Municipales de algún departamento del interior del país. Por su parte, otro tercio de los senadores de los partidos tradicionales han ocupados cargos con anterioridad al cargo de Senador en el Poder Ejecutivo, en tareas que van desde la asesoría al Poder Ejecutivo hasta la propia presidencia de la República. Aproximadamente un sexto de los senadores de los partidos tradicionales tuvieron como cargo público anterior el cargo de Diputado. Finalmente, sólo un décimo de los senadores de los partidos tradicionales no ha tenido actividad anterior en cargos públicos.

En definitiva, se aprecia una clara diferencia en las formas de ejercicio de la actividad pública anterior de los senadores de los distintos partidos políticos. Mientras los senadores frenteamplistas vienen de una trayectoria basada en la continuidad de la carrera parlamentaria y también la bancada 
frenteamplistas es la que presenta mayor proporción de senadores sin experiencia previa. Desde el lado de los legisladores de los partidos tradicionales, mayoritariamente han ejercido la actividad pública en cargos del Poder Ejecutivo.

Parte de la actividad pública anterior de los senadores tiene que ver con el resultado electoral que su partido obtenga en las Elecciones Nacionales. Si el partido obtiene el mando del Poder Ejecutivo por varios años, los miembros del partido tendrán mayores posibilidades de ejercer cargos en el Ejecutivo, elemento que como se verá es muy importante a los efectos de lograr una trayectoria política duradera e importante. Por el contrario, los senadores miembros de partidos políticos que no tengan el mando del Poder Ejecutivo, tendrán menos posibilidades de formarse en la actividad pública antes de llegar al Senado, en todo caso, ese aprendizaje de la actividad pública deberá ser desarrollado en otros ámbitos, sea ejerciendo como Edil o Diputado.

\section{ABANDONO DEL CARGO DE SENADOR HACIA OTROS CARGOS PÚBLICOS}

Otra dimensión abordada en la investigación ha sido el cambio de cargo producido durante el período para el cual fueron electos los senadores, esto es el abandono de la banca para el que fue electo a los efectos de ejercer otro tipo de cargo público, generalmente en el Poder Ejecutivo.

El objetivo es observar cuál es la dimensión de la rotación en el mismo período entre el Legislativo y el Ejecutivo porque como se apuntó antes, es desde el Senado que surgen por lo general los ministros y los presidentes de organismos o entes estatales.

CUADRO 3 - EVOLUCIÓN DE LOS CARGOS PÚBLICOS OCUPADOS DURANTE EL PERIODO PARA EL QUE FUERON ELEGIDOS (1985-2010)

\begin{tabular}{|l|c|c|c|c|c|}
\hline CARGO & 1985-1990 & 1990-1995 & 1995-2000 & 2000-2005 & 2005-2010 \\
\hline Diputado & 6 & 0 & 3 & 3 & 0 \\
Intendente & 0 & 0 & 0 & 0 & 3 \\
Subsecretario de Ministerio & 0 & 0 & 0 & 0 & 3 \\
Ministro & 13 & 11 & 23 & 19 & 18 \\
Presidente de organismo o ente & 3 & 3 & 0 & 0 & 0 \\
Diplomático & 3 & 0 & 0 & 0 & 0 \\
No ocupó & 75 & 80 & 75 & 78 & 76 \\
Sin dato & 0 & 6 & 0 & 0 & 0 \\
Total & 100 & 100 & 100 & 100 & 100 \\
\hline
\end{tabular}

FUENTE: el autor.

GRÁFICO 1 - EVOLUCIÓN DE LOS CARGOS PÚBLICOS OCUPADOS DURANTE EL PERIODO PARA EL QUE FUERON ELEGIDOS (1985-2010)

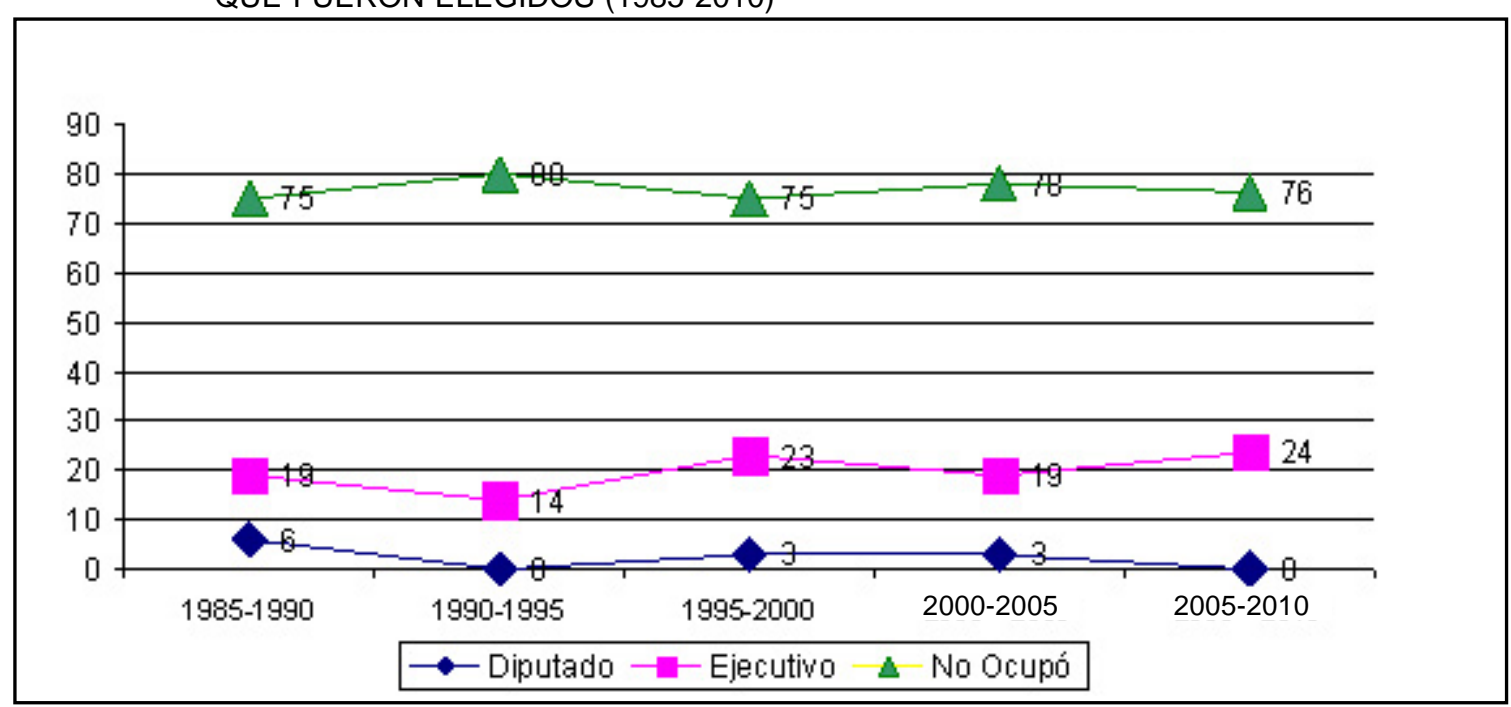

FUENTE: el autor. 
El gráfico muestra una considerable continuidad en todas sus cifras. La cifra de los senadores que no ocuparon cargos fuera de la Cámara Alta, fuera del cargo para el que fueron electos ha oscilado entre el $75 \%$ y el $80 \%$, lo que representa una continuidad bastante constante. Mientras tanto el dato referente a los senadores que abandonaron sus cargos para pasar del cargo legislativo a un cargo ejecutivo, en su gran mayoría cargos ministeriales, osciló entre el $14 \%$ y el $24 \%$, los cambios producidos para cada uno de los períodos tiene, entre otras, explicaciones políticas. Así, en el primer período se buscó una concertación para hacer la transición y consolidar la democracia por lo que hubo participación de los dos partidos tradicionales en el gobierno colorado. El nivel más bajo de participación de senadores en el Ejecutivo se da en el período de gobierno blanco, donde todos los senadores que abandonaron sus cargos legislativos para ejercer cargos en el Ejecutivo fueron del Partido Nacional. El período en que se nota un primer gran envión en la circulación entre el Legislativo y el Ejecutivo se observó en la legislatura 1995-2000, gobierno del Partido Colorado pero con una coalición con el Partido Nacional. Mientras, en el período 2000-2005 se volvió a los niveles de 19851990 en cuanto a la circulación entre el Legislativo y el Ejecutivo. En la actual legislatura, 2005-2010, se nota un nuevo ascenso en la circulación entre el Poder Legislativo y el Poder Ejecutivo, donde todos los senadores que han abandonado su banca en el Parlamento para ocupar un cargo en el Ejecutivo pertenecen a fila del Frente Amplio.

El hecho quizás más destacable que se ha dado a lo largo de las cuatro primeras legislaturas estudiadas es que el Frente Amplio (y en su momento el Nuevo Espacio) siempre había quedado fuera de los gobiernos de los partidos tradicionales. Ninguno de sus senadores abandonó su cargo para ocupar otro tipo de cargo público. A su vez, con el ascenso de la izquierda al mando del Ejecutivo, sucede lo mismo, ningún Senador de los partidos tradicionales ha abandonado su banca para ocupar un cargo en el Ejecutivo. Si bien no es un dato extraño debido a las diferentes posturas ideológicas, sí es un dato relevante a la hora del análisis, la oposición siempre quedó fuera del gobierno.

Las cifras permiten corroborar que los ministerios generalmente son comandados por senadores que abandonan sus cargos para ejercer en el Ejecutivo. $\mathrm{O}$ a la inversa, que los senadores abandonan los cargos para el cual son elegidos a fin de ocupar un puesto en el Ejecutivo. Si bien los datos no son concluyentes, se marca una tendencia bastante estable que aparentemente se mantiene en el caso del gobierno de izquierda.

\section{PERMANENCIA O MOVILIDAD PARLA- MENTARIA}

El presente apartado estudiará la movilidad que pueda existir a lo largo de la carrera política de los senadores entre los distintos partidos, es decir el pase de un partido a otro (en caso que la hubiera) a lo largo de la vida de los actuales senadores estudiados.

CUADRO 4 - CANTIDAD DE PARTIDOS A LOS QUE
\begin{tabular}{|c|c|}
\hline HA PERTENECIDO (2005-2010) \\
\hline $\boldsymbol{N}$. & $\mathbf{2 0 0 5}-\mathbf{2 0 1 0}$ \\
\hline 1 & $84 \%$ \\
2 & $16 \%$ \\
Total & $100 \%$ \\
\hline
\end{tabular}

\section{FUENTE: el autor.}

La gran mayoría de los senadores se han mantenido siempre en el mismo partido político a lo largo de su carrera política.

En todos los casos en que se anota la participación en dos partidos políticos se deben a traspasos desde los partidos tradicionales hacia el Frente Amplio. Uno de los casos se produjo antes de la dictadura militar. Dos casos se produjeron con la creación del Encuentro Progresista-Frente Amplio, donde hubo una corriente del Partido Nacional que se sumó a la izquierda uruguaya. Otro de los casos corresponde a un cambio desde el Partido Colorado hacia el Frente Amplio producido luego de las Elecciones Nacional del año 1999. Por último, otro grupo del Partido Nacional se ha movido hacia el Frente Amplio para competir en las últimas elecciones (2004), en la cuál fueron electos los senadores de la actual legislatura (2005-2010).

De estos datos surge que los políticos tienen un fuerte arraigo partidario, el cual lleva a un proceso largo de carrera política y políticopartidaria.

Sin embargo, como se verá en el siguiente apartado la renovación de la Cámara es bastante alta, 
por lo tanto no puede decirse que el mantenerse en el mismo partido signifique ser reelecto, aunque notoriamente mantenerse en los puestos altos del mismo partido tiene gran influencia.

El Cuadro 5 muestra los cambios de sectores producidos a lo largo de la carrera política de los senadores.

CUADRO 5-CANTIDAD DE SECTORESALOS QUE HA PERTENECIDO (2005-2010)

\begin{tabular}{|c|c|}
\hline SECTORES & $\mathbf{2 0 0 5 - 2 0 1 0}$ \\
\hline 1 & $45 \%$ \\
2 & $48 \%$ \\
3 & $5 \%$ \\
4 & $2 \%$ \\
Total & $100 \%$ \\
\hline
\end{tabular}

FUENTE: el autor.

Teniendo en cuenta que el 16\% de los senadores actuales ha participado de más de un partido, quiere decir que han participado de más de un sector. De lo anterior surge que más de la mitad de los senadores de la actual legislatura ha pertenecido durante toda su trayectoria política al mismo partido y al mismo sector.

Resulta además interesante que, de los senadores que han pertenecido a un solo partido a lo largo de su carrera política, el $90 \%$ ha pertenecido a uno o dos sectores, con lo cuál la movilidad política aparece como un elemento muy escaso.

Estos datos indican una fuerte institucionalidad de los partidos políticos y una fuerte permanencia de los políticos en el partido, la pertenencia a un único partido político a lo largo de la carrera política parece ser un elemento en común que comparten la gran mayoría de los senadores, y que puede ser uno de los factores que conduzcan a elementos de permanencia en puestos públicos representando al partido.

Con respecto a la trayectoria y renovación parlamentaria, el análisis se realizará a través del estudio de la cantidad de legislaturas ocupadas por los integrantes del universo de estudio, legislaturas ocupadas tanto en la Cámara de Diputados como en la Cámara de Senadores.

El análisis se hará de la siguiente manera: primero se analizará cuál fue el primer cargo legislativo nacional ejercido. En segundo lugar con el análisis de la cantidad de legislaturas como Diputado ocupadas por los senadores estudiados, sea ocupado el cargo de Diputado antes o después del cargo de Senador, también se tendrá en cuenta quienes no ocuparon nunca el cargo de Diputado. Y el tercer elemento a considerar es la cantidad de legislaturas que han ejercido hasta el momento en el cargo de Senador.

De aquí al final de la sección se analizarán los datos recabados en cuanto a la cantidad de legislaturas como Diputado y la cantidad de legislaturas como Senador para el universo de estudio.

En el Cuadro 6 se analiza el primer cargo legislativo ocupado por los senadores pertene-cientes a la actual legislatura (2005-2010).

CUADRO 6 - PRIMER CARGO LEGISLATIVO OCUPADO

\begin{tabular}{|c|c|}
\hline CARGO & $\mathbf{2 0 0 5}-\mathbf{2 0 1 0}$ \\
\hline Diputado & $47 \%$ \\
Senador & $53 \%$ \\
Total & $100 \%$ \\
\hline
\end{tabular}

Del cuadro se desprende que aproximadamente la mitad de los senadores han tenido alguna experiencia en la Cámara de Representantes, como escalón previo al pasaje al Senado. Por lo tanto, del mismo cuadro se desprende que la mitad de los senadores que forman parte de la actual legislatura no han tenido experiencia previa en el Legislativo antes de tomar posesión de la banca senatorial.

Los datos son muy similares a los recabados para las legislaturas anteriores. En aquella oportunidad se había llegado a la conclusión que "a nivel general el 46\% de los senadores estudiados nunca ocuparon una banca en la Cámara Baja, significa que al entrar al Senado no tenían experiencia a nivel del Poder Legislativo" (idem, p. 19).

Los datos parecen ser muy estables desde la restauración democrática, por lo tanto, no parece apresurado adelantar que la mitad de los senadores de cada legislatura han tenido una especie de carrera política ascendente, pasando por la Cámara de Diputados para llegar a la Cámara de Senadores. A su vez, la otra mitad de los senadores no han tenido experiencia previa como diputados, en 
estos casos se encuentran distintas situaciones: personas que ocupan la banca en el Senado luego de haber ejercido algún cargo en el Ejecutivo, otros que la ocupan como medio para llegar a cargos más altos proviniendo de la base del partido, y otras situaciones particulares que se irán describiendo y analizando en el transcurso del informe.

\section{CUADRO 7-CANTIDAD DE LEGISLATURAS COMO} DIPUTADO

\begin{tabular}{|c|c|}
\hline LEGISLATURAS & $\mathbf{2 0 0 5 - 2 0 1 0}$ \\
\hline 0 & $53 \%$ \\
1 & $29 \%$ \\
2 & $11 \%$ \\
3 & $8 \%$ \\
Total & $100 \%$ \\
\hline
\end{tabular}

FUENTE: el autor.

El 29\% de los senadores de la actual legislatura ocupó una sola vez el cargo de Diputado antes de llegar al cargo de Senador. De esta forma, este 29\% de los senadores ocupó al menos durante dos períodos una banca en el Parlamento. Este dato es prácticamente idéntico al registrado para las legislaturas anteriores (1985-2005), donde se había encontrado que el " $28 \%$ de los senadores estudiados ocupó una sola vez el cargo de Diputado [...]” (idem, p. 20).

Por último, y para simplificar la lectura, se tomarán a quienes ocuparon más de una vez la banca como diputados como un único conjunto, de esta forma, el restante 19\% ocupó por más de una legislatura la banca de Diputado, este dato va afirmando una permanencia dentro del Parlamento de al menos tres legislaturas, sea como Diputado o como Senador, ese $19 \%$ ejerció al menos dos de Diputado y una de Senador. En estos casos la permanencia va transformando a la política como un medio de vida.

Analizando los datos para cada uno de los partidos políticos se encuentra que el partido que más senadores sin experiencia previa en la Cámara de Diputados aporta al Senado es el Partido Nacional.

Dentro de los senadores del Frente Amplio, la mitad no ha tenido experiencia previa en la Cámara de Representantes, mientras que casi la otra mitad ha tenido una única experiencia en la Cámara Baja.

\section{CUADRO 8-CANTIDAD DE LEGISLATURAS COMO} SENADOR

\begin{tabular}{|cc|}
\hline LEGISLATURAS & $\mathbf{2 0 0 5 - 2 0 1 0}$ \\
\hline 1 & $50 \%$ \\
2 & $18 \%$ \\
3 & $24 \%$ \\
4 & $5 \%$ \\
5 & $3 \%$ \\
Total & $100 \%$ \\
\hline
\end{tabular}

El cuadro anterior muestra la cantidad de legislaturas como Senador ocupadas por los integrantes de la actual legislatura. Los datos muestran que el 50\% de los senadores ha ocupado una única legislatura como Senador, es un dato significativo que anuncia movilidad en la Cámara Alta. En segundo lugar, el 18\% de los senadores han ocupado una segunda legislatura en esta Cámara lo cual marca una cierta continuidad. Y en tercer lugar, quienes han ocupado más de dos legislaturas el cargo de Senador, que se mantuvieron por más de tres legislaturas en el cargo senatorial son el $32 \%$ restante, quienes tienen una larga trayectoria como senadores de la República.

El Partido Colorado es el que tiene a todos sus senadores sin experiencia previa en la Cámara Alta. Sin embargo hay que destacar que los senadores de este partido son personas de trayectoria de peso y en dos de los tres casos con una larga carrera política. De los tres senadores del Partido Colorado se encuentra: un ex-Presidente de la República, ex-Ministro y ex-Diputado; un ex-Intendente y exPresidente de un ente estatal y un ex-Ministro.

El partido que proporcionalmente más hombres nuevos ha aportado al Senado, al igual que en personas sin experiencia previa como diputados, es el Partido Nacional, con aproximadamente la mitad de sus senadores sin experiencia previa en esta Cámara. Fenómeno similar sucedió en el estudio de legislaturas anteriores, donde se había constatado que el 70\% de los senadores del Partido Nacional no tenían experiencia previa en el Senado (idem).

El Frente Amplio con un poco menos de la mitad de sus senadores sin experiencia en el Senado es el partido que aporta menor proporción de senadores sin experiencia en esta Cámara.

Con respecto a la continuidad dentro del Se- 
nado, el Partido Colorado es netamente quien proporcionalmente menos repetidores tiene, hecho que se desprende al ser el partido que ofrece a los senadores sin experiencia previa en el Senado.

La continuidad prolongada en la Cámara de Senadores aparece como una tarea compleja, sin embargo el $32 \%$ de los senadores de la actual legislatura ha podido mantenerse por más de dos legislaturas en el Senado. Este hecho contrasta bastante con lo encontrado en las legislaturas anteriores, donde "solo el $17 \%$ de los senadores estudiados ha podido mantenerse por más de dos legislaturas en el Senado" (idem, p. 22).

El Frente Amplio tiene en sus filas un 36\% de senadores que fueron elegidos por más de dos períodos como senadores. Por su parte, el Partido Nacional registra una menor cantidad proporcional de legisladores electos para más de dos legislaturas con un 27\%. El Partido Colorado no presenta ninguno de sus senadores con tres o más legislaturas ejercidas en el Senado.

El incremento en la experiencia por parte de los legisladores del Frente Amplio puede ser considerado una consecuencia del incremento en el caudal electoral de éste partido a lo largo del período estudiado, lo cual permite que los senadores se mantengan en sus cargos por más tiempo debido a que el aumento en la cantidad de votos significa un aumento en la cantidad de bancas.

La renovación parlamentaria ha sido analizada en otros estudios, no es el objetivo analizar las tasas de renovación parlamentaria elección tras elección, sino que se trata de establecer permanencias o movilidades de los senadores dentro del Parlamento en general, sin duda que con los datos que se han relevado podría hacerse un estudio comparado con estos estudios ya apuntados, pero no fue ni el objetivo inicial ni es el objetivo final del presente estudio. Sin embargo se harán algunas referencias a estos estudios a efectos de guiar el análisis final de este apartado.

Una de las razones apuntadas por la cual la tasa de renovación parlamentaria sea tan alta es que por lo general no hay dos elecciones consecutivas en que un mismo partido presente la misma oferta de candidatos al Parlamento, esto explicaría en parte la alta rotación que se ha visto en los cuadros, la falta de experiencia tanto en la Cámara de Diputados como en la Cámara de Senadores y la falta de continuidad de los senadores dentro del
Parlamento podría ser explicada entonces por la conformación de las listas elección tras elección.

Además Chasquetti ha mostrado en su estudio que "un porcentaje importante de legisladores no buscan la reelección. [...] Por tanto, esas cifras demuestran que la tasa de renovación parlamentaria cuenta con un quantum casi constante del 30\% de legisladores que no deciden proseguir sus carreras legislativas" (CHASQUETTI, 2000, p. 13) otro elemento a considerar es pues que la falta de experiencia previa puede ser explicada también por la falta de interés de los parlamentarios por ser reelectos.

El mismo autor apunta que "se ha observado que la tasa de renovación parlamentaria es alta durante las últimas tres elecciones. Sin embargo, se detecta también una lenta y sostenida caída. En 1989 se ubicó en el 66,1\%, en 1994 bajó al 63,8\% y en 1999 volvió a descender al 53\%”, para poder explicar esto sin duda alguna habría que haber tomado en cuenta que a medida que el quiebre institucional va quedando más lejos en el tiempo, mayor es la probabilidad que los parlamentarios hayan ocupado bancas (ibidem).

Como se apuntó más arriba mucho tienen que ver los cambios en los resultados electorales para la falta de experiencia de los senadores, sea como diputados u ocupando una única legislatura como senadores. "El principal factor explicativo de la renovación y reelección legislativa es la volatilidad electoral del conjunto del sistema”, así queda planteada una de las posibles, quizás la principal causa de la falta de experiencia y permanencia en el poder Legislativo (idem, p. 14).

Hay renovación alta y sin embargo existe también un conjunto de profesionales de la política que se han mantenido durante muchos años en los cargos legislativos, viviendo de la política y del Estado.

\section{LA TRAYECTORIA POLÍTICA COMO “TIPO IDEAL” Y LA PROFESIONALIZA- CIÓN POLÍTICA}

Tomando la literatura francesa se plantea reconstruir las carreras políticas mediante la utilización de tres dimensiones: el tiempo de formación, el itinerario de rotación y la posición en cuanto a la experiencia en política.

Así, analizando el tiempo de formación política se puede distinguir entre quienes se han dedi- 
cado a la política conformando una carrera y quienes tienen actividad política en forma más esporádica. Para analizar a quienes han conformado una carrera política, quienes se han dedicado de forma profesional al ejercicio de la política, es necesario analizar tanto la edad de ingreso a la actividad política como la edad de ingreso al partido, así como el tiempo en puestos políticos.

A su vez puede analizarse la trayectoria política de los políticos distinguiendo a través del itinerario de actividad en cargos políticos y cargos públicos. Así es posible analizar la "movilidad” de quienes han ocupado cargos, por un lado entre quienes tienen puestos móviles (no permanecen en el puesto) y quienes tienen varios puestos (pero permanecen en la actividad política). Por otro lado, es posible analizar los políticos a través del itinerario de "continuidad” en cargos públicos, de esta forma se distingue, por un lado entre quienes han tenido continuidad a lo largo del tiempo en cargos públicos, y por otro lado entre quienes han tenido interrupciones a lo largo de su carrera política pública.

Finalmente, cabe distinguir las carreras políticas a través de la "posición” y el nivel de especialización. De esta forma, se distingue entre quienes son especialistas en determinado tema, tienen una expertise y habilidades adquiridas para formar parte de los equipos políticos para analizar determinadas temáticas. Por otro lado, se encontrarían quienes no tienen esa especialización, sino que poseen un background técnico pero que no se han especializado políticamente en alguna temática.

Así, el tiempo dedicado a la carrera política aparece como un elemento central en la política como profesión.

El tiempo en la vida dedicado a la actividad política puede analizarse también a través de las edades medias de ingreso a los distintos puestos en los que han participado los senadores estudiados.

Así, como se especificó más arriba, la edad media de Inicio en la actividad política es de aproximadamente 20 años de edad. Siguiendo la trayectoria, el promedio del ingreso formal al partido político se da dos años más tarde. Luego existe un tiempo bastante prolongado de actividad política sin participar en puestos públicos, registrándose la mediana de edad para el ingreso al primer cargo público a los 37 años de edad, es decir, casi 17 años después de haber iniciado la actividad política. El ingreso al Parlamento aparece como un escalón posterior, al menos en lo referente a la edad, en la carrera política de los senadores, así se registra que la edad mediana para el ingreso al Parlamento es de 47 años, mientras que la edad mediana para el ingreso al Senado es de 52 años.

Analizando estas medianas de edades, se obtiene que la carrera política antes de llegar al Senado insume unos 32 años de actividad política.

En investigaciones recientes sobre el Senado uruguayo se había constatado que "desde que el individuo ingresa en la estructura partidaria hasta que ocupa su primer cargo público han pasado nueve años y medio, por lo tanto, puede decirse que se requieren varios años de actividad partidaria hasta que el miembro de partido logra acceder a su primer cargo público" (BOTTINELLI, 2005, p. 14). Comparando los resultados de la actual legislatura (2005-2010) con las legislaturas anteriores (1985-2005), se encuentra un aumento en la cantidad de años requeridos para pasar de la estructura político-partidaria a ocupar un cargo público. Este retraso puede ser explicado a través de los cambios electorales producidos en las últimas Elecciones Nacionales, como se indicó más arriba, los senadores del Frente Amplio han tenido menores posibilidades de ocupar puestos públicos con anterioridad, ya que el gobierno nacional estuvo en manos de los Partidos Tradicionales, quienes conformaron sus gabinetes ministeriales y los directorios de las empresas públicas con políticos y técnicos provenientes de sus propias filas políticas.

A su vez, desde el primer cargo público ocupado hasta llegar al Parlamento, en la actual legislatura (2005-2010), se requirieron diez años de actividad política-pública, mientras que para las legislaturas anteriores (1985-2005) "desde que la persona media ocupa su primer cargo público a los 35 años hasta que llega al Parlamento han pasado más de 11 años de actividad pública para ocupar una banca en el Legislativo” (ibidem). A su vez, para llegar al Senado en las legislaturas anteriores se requirieron seis años más de actividad políticas, mientras que para la actual legislatura se requirieron cinco años. 
Estos datos muestran que para tomar la política como profesión, se requiere una fuerte inversión de recursos y de tiempo, a su vez, mantenerse en la actividad pública en forma continua depende en muchos casos de los resultados electorales, así como de la trayectoria política y profesional de las personas. Sin embargo, lo que surge de la investigación es que, desde que se inicia la actividad política hasta ocupar cargos públicos se requiere una trayectoria promedio de entre 10 y 15 años, mientras que para llegar al Parlamento se requieren aproximadamente diez años más de actividad, y para alcanzar el Senado cinco años más. Así, desde que se inicia en la actividad política en forma profesional se requieren unos 30 años de actividad política para alcanzar un puesto en el Senado.

Existen algunas diferencias en las trayectorias entre los senadores de los partidos tradicionales y los senadores de la izquierda. Los senadores de izquierda presentan un promedio de edad más elevado al momento de ingresar al Parlamento y al Senado. A su vez, mientras los senadores de izquierda tienen una actividad profesional más volcada hacia las profesiones tradicionales, los senadores de los partidos tradicionales tienen un mayor pesos de las profesiones de tipo liberal.

El tipo de organización social en la que se ha participado previo a acceder al Senado también muestra diferencias entre los dos grandes grupos de partidos. Mientras los senadores de los partidos tradicionales tienen una mayor participación en Cámaras Empresariales y en Instituciones deportivas, los senadores frenteamplistas tienen una mayor participación en Movimientos Estudiantiles y Sindicatos de trabajadores.

A su vez, la otra distinción importante en las trayectorias de los senadores está en que los senadores de los partidos tradicionales han tenido mayor experiencia en cargos públicos ejecutivos con anterioridad a ocupar la banca en el Senado que los parlamentarios de izquierda.

Más allá de las diferencias encontradas para los distintos partidos políticos, hay carreras políticas que encuentran puntos comunes más allá de los partidos, así el comienzo de la actividad política a edades tempranas y participar en organizaciones sociales es un elemento importante que se repite en la gran mayoría de los senadores de la actual legislatura (2005-2010). Otro ele- mento importante es mantenerse en el mismo partido político de forma de llevar una carrera política que incorpore el ocupar cargos públicos o cargos políticos notorios dentro del partido.

\section{CONCLUSIONES}

"Quien hace política aspira al poder; al poder como medio para la consecución de otros fines (idealistas o egoístas) o al poder 'por el poder', para gozar del sentimiento de prestigio que él confiere" (WEBER).

De acuerdo a la evidencia empírica puede afirmarse que quienes se iniciaron en los partidos tradicionales lo hicieron a edades más tempranas tanto en la actividad político-partidaria así como al ocupar el primer cargo público. Los partidos tradicionales han tenido una acumulación histórica de gobierno y control del aparato estatal que facilita el acceso más temprano a las esferas públicas.

La reconstrucción de las trayectorias partidarias de los senadores muestra una notable continuidad en sus lealtades partidarias en todos los partidos.

En referencia a la permanencia o movilidad dentro del Parlamento, ambos rasgos coexisten. Se puede afirmar que cerca de la mitad de los senadores registraron experiencia previa en la Cámara Baja mientras que la otra mitad de legisladores muestra una alta rotación y renovación en el Parlamento sin ninguna actividad anterior en el Poder Legislativo previa a ocupar la banca en el Senado.

Respecto a las continuidades dentro del senado se dan datos muy relevantes que muestran que la mitad de los legisladores pueden considerarse dentro de los políticos con alta profesionalización. Por un lado, una quinta parte de los senadores ha ocupado dos bancas como senadores, siendo que en muchos casos además tuvieron bancas como diputados. Por otro, un tercio de los senadores ha tenido una trayectoria parlamentaria muy prolongada en tiempo, con casos extremos de hasta cinco legislaturas como senadores.

Otra dimensión significativa de profesionalización de los elencos políticos es la circulación entre el Poder Legislativo y el Ejecutivo. Una cuarta parte de los senadores han abandonaque mayor cantidad de políticos ascendiera rápidamente en la escala de cargos. 
Uno de los tipos de carreras políticas marcadas se basa en la acumulación constante en la carrera a través de ocupar distintos puestos que van desde los puestos legislativos locales en el ámbito municipal, hasta los puestos legislativos nacionales.

El otro tipo de carrera política identificado es el denominado profesionalización endógena, el cual se da al interior del aparato estatal, este tipo de carreras es el comienza a través de ocupar puestos públicos en el Ejecutivo, estas carreras luego combinan el pasaje de puestos ejecutivos a puestos legislativos.

Eduardo Bottinelli (eduardo.bottinelli@gmail.com) es Licenciado en Sociología y ayudante de investigación de la Comisión Sectorial de Investigación Científica (CSIC) del Departamento de Sociología de la Universidad de la República (Udelar, Uruguay).

\section{REFERENCIAS BIBLIOGRÁFICAS}

AGUIRRE, R. 2001. La subrepresentación de las mujeres en la política : un desafío para el siglo XXI. In : MALLO, S. \& SERNA, M. (orgs.). Seducción y desilusión : la política latinoamericana contemporánea. Montevideo : Banda Oriental.

BARRAN, J. P. \& NAHUM, B. 1986. Batlle, los estancieros y el imperio británico. Montevideo : Banda Oriental.

BEST, H. \& COTTA, M. 2000. Parlamentary Representatives in Europe (1848-2000). Oxford: Oxford University.

BOTTINELLI, E. 2005. ¿Permanencia o movilidad? La trayectoria política de los senadores en el Uruguay contemporáneo. Montevideo. Dissertação (Mestrado). Universidad de la República.

2007. ¿Permanencia o movilidad? La trayectoria política de los senadores en el Uruguay contemporáneo. Montevideo : UDELAR.

BOURDIEU, P. 2000. Intelectuales, política y poder. Buenos Aires : Eudeba.

CHASQUETTI, D. 2000. La renovación del Parlamento (1985-1999). Documento de trabajo, n. 20. Montevideo : Instituto de Ciencia Política.

DAHL, R. 1989. La poliarquía. Madrid : Tecnos.

DOGAIN, M. 1999. Les professions propices à la carrière politique. Osmoses, filières et viviers. In : OFFERLÉ, M. (ed.). La profession politique XIXe-XXe siècles. Paris : Belin.

DUVERGER, M. 1961. Los partidos políticos.
Ciudad de México : Fondo de Cultura Económica.

FITOUSSI, J. P. \& ROSANVALLON, P. 1997. La nueva era de las desigualdades. Buenos Aires : Manantiales.

GARCIA, J. 2006. El origen social y reclutamiento político de los senadores. Montevideo. Dissertação (Mestrado). Universidad de la República.

GONZÁLEZ, L. 1995. Estructuras políticas y democracia en Uruguay. Montevideo : Fondo de Cultura Universitaria.

MALLO, S.; PATERNAIN, R. \& SERNA, M. 1995. Modernidad y poder en el Río de la Plata. Colorados y Radicales. Montevideo : Trazas.

MALLO, S. \& SERNA, M. 2001. Seducción y desilusión : la política latinoamericana contemporánea. Montevideo : Banda Oriental.

MICHELS, R. 1987. Los partidos políticos. Un estudio sociológico de las tendencias oligárquicas de la democracia moderna. Buenos Aires : Amorrortu.

MILLS, C. W. 1987. La elite del poder. Ciudad de México : Fondo de Cultura Económica.

MOREIRA, C. 1997. Democracia y desarrollo en Uruguay. Montevideo : Trilce.

2004. Final del juego. Del bipartidismo al triunfo de la izquierda. Montevideo : Trilce.

NOHLEN, D. 1994. Sistemas electorales y partidos políticos. Ciudad de México: Fondo de Cultura Económica. 
NORRIS, P. \& LOVENDUSKI, J. 1997. United Kingdom. In : NORRIS, P. (ed.). Passages to Power. Legislative Recruitment in Advanced Democracies. Cambridge : Cambridge University.

OFFERLÉ, M. 1999. La profesión politique (XIXe-XXe siècles). Paris : Belin.

2004. Los partidos políticos. Santiago de Chile : LOM.

PANEBIANCO, A. 1990. Modelos de partido. Madrid : Alianza.

PARETO, W. 1987. Formas y estructuras sociales. Madrid : Alianza.

REAL DE AZÚA, C. 1981. El patriciado uruguayo. Montevideo : Banda Oriental.

SERNA, M. 2004. Reconversão democrática das esquerdas no Cone Sul. São Paulo : USC.
2005. Las vías hacia el poder político : bases sociales y carreras políticas de los parlamentarios uruguayos. In: MAZZEI, H. (org.). El Uruguay desde la Sociología IV. Montevideo: UDELAR.

2006. La política como profesión y las profesiones de la política. Una mirada de las trayectorias biográficas de parlamentarios uruguayos. In: MAZZEI, H. (org.). El Uruguay desde la Sociología V. Montevideo: UDELAR.

VILLARÓ, A. 2006. Las elites parlamentarias y sus desempeños laborales en el Uruguay (19852003). Montevideo. Dissertação (Mestrado). Universidad de la República.

WEBER, M. 1984. La política como vocación. Montevideo : Fondo de Cultura Universitaria. 


\section{THE POLITICAL CAREERS OF MEMBERS OF THE SENATE IN URUGUAY: CHANGES OR CONTINUITIES FOLLOWING THE TRIUMPH OF THE LEFT?}

\section{Eduardo Bottinelli}

This article looks at diverse types of political trajectories, focusing on the impact of political change on Uruguayan parliamentary elites after the end of the dictatorship. With regard to a segment of the political elite, we are interested in revealing the two-sided movement made up of political party continuity among leadership and of inter-party mobility, both flowing electoral changes that are underway. Furthermore, we analyze the modalities of political careers of parliament members and circulation between parliamentary posts and other State positions. Our work is based on research into the trajectory of Uruguayan senators during the 2005-2010 period and compares it to that of previous legislatures also belonging to the post-dictatorship period (1985-2005). For the current legislature we have used the method of multiple biographic trajectories, studying 38 senators with mandates during the period, using personal and parliamentary documentary sources and published biographies as well as our own research and interviews carried out directly with the senators. Our study enables us to identify patterns common to members of parliament as well as to explore the differences in the political trajectory of senators from traditional and leftist parties.

KEYWORDS: parliamentary elites; political trajectories; political parties.

\section{LES CARRIÈRES POLITIQUES DES SÉNATEURS EN URUGUAY: CHANGEMENTS OU CONTINUITIÉ FACE À LA RÉUSSITE DE LA GAUCHE?}

\section{Eduardo Bottinelli}

L'article discute les divers types de trajectoire politique et met en relief l'impact du changement politique au sein des élites parlementaires de l'Uruguay après la dictature. Notre intérêt est de montrer, par rapport à une tranche de l'élite politique, le double mouvement de continuité de la politique des partis par les dirigéants politique et de la mobilité inter-partis ; ces mouvements sont issus des changements électoraux en cours. En plus, les modalités des carrières politiques du groupe parlementaire et la circulation entre les postes parlementaires et d'autres fonctions de l'État sont également analysés. Le travail s'appuie sur une recherche sur la trajectoire des sénateurs uruguayens de 2005 à 2010 et compare cette période aux législatures antérieures, toujours de la période postérieure à la dictature (1985-2005). Pour la législature actuelle, on utilise la méthode de trajectoires biographiques multiples, et on étudie 38 sénateurs exerçant le mandat dans cette période, en se servant des sources documentaires personnelles, parlementaires et biographies publiées, ainsi que des recherches et des entretiens menés directement auprès des sénateurs. L'étude permet non seulement d'identifier des standards communs chez les parlementaires, mais encore d'exploiter les différences des trajectoires politiques des sénateurs des partis traditionnels et de ceux de la gauche.

MOTS-CLÉS: élites parlementaires; trajectoires politiques; partis politiques; Uruguay. 